\title{
Functional outcome of titanium elastic nailing in midclavicular fractures
}

\author{
Arun Gopalakrishnan ${ }^{1}$, Sreesobh KV ${ }^{2, *}$, Jijo Jose ${ }^{3}$ \\ 1,3Assistant Professor, ${ }^{2}$ Associate Professor, Dept. of Orthopedics, P.K Das Institute of Medical Sciences, Vaniamkulam, \\ Palakkad, Kerala, India
}

*Corresponding Author: Sreesobh KV

Email: drsreesobh@gmail.com

\begin{abstract}
Introduction: With changing trends in the treatment of displaced mid-third clavicle fractures, more and more fractures are treated surgically. Even though plating remains the gold standard, minimally invasive technique with Titanium Elastic Nail (TEN) is gaining popularity. In this paper, we are assessing the functional outcome of mid third clavicle fracture treated with TEN.

Materials and Methods: Thirty patients with midclavicular fractures were treated with TEN. Functional and radiological results were evaluated at 3, 6 and 12 months. Implant was removed in all cases after union.

Results: All cases united without any infection and constant scores were 91.3, 96.3 and 98.7 at 3, 6 and 12 months respectively. $46 \%$ complained of prominent implant medially and in three patients we had to trim the medial end of implant. Clavicular shortening observed were also in acceptable limits.

Conclusion: Titanium elastic nailing is a simple, safe, cosmetically preferred and minimally invasive technique for midclavicular fractures with good functional outcome and fewer complications.
\end{abstract}

Keywords: Midclavicular fractures, Titanium elastic nailing (TEN).

\section{Introduction}

Clavicle fractures are common injuries with an incidence of $5-10 \%$ of all fractures. ${ }^{1}$ About $80 \%$ of theses fractures are midshaft fractures. ${ }^{2,3}$ Almost all midshaft clavicular fractures were treated conservatively in the past, but recent literatures suggest that the incidence of symptomatic nonunion and malunion are high. ${ }^{4-6}$ Hence more and more fractures are treated surgically even though the traditional indications for surgical fixation are impending skin perforation, neurovascular compromise, floating shoulder and gross displacement.

Various methods of fixation have been described in literature, of which plating and intramedullary nailing are the most popular ones. ${ }^{7}$ Intramedullary nailing using titanium elastic nail (TEN) is technically easy, cheap and minimally invasive method with fewer complications. ${ }^{8,9}$ Even though plate osteosynthesis is considered the gold standard but it has higher complication rates. ${ }^{10}$

\section{Materials and Methods}

30 midshaft clavicular fractures treated with TEN in PK Das institute of Medical sciences between January 2014 to August 2016 were included in the study. 10 patients had fracture with a wedge fragment. One was segmental fracture of middle third.

All the surgeries were done under general anaesthesia. Patient was positioned supine with sand bag in the interscapular region. Head was turned to the opposite side. A $1 \mathrm{~cm}$ incision was made just lateral to the sternoclavicular joint in line with clavicle. The anterior cortex was opened with an awl $1.5 \mathrm{~cm}$ lateral to the joint. A 2 or $2.5 \mathrm{~mm}$ TEN was introduced into the canal with the help of T-handle and advanced till the fracture site. The fracture was then reduced with closed manipulation or percutaneous use of towel clips. If closed reduction was not possible a $2 \mathrm{~cm}$ incision was made over the fracture site and mini open reduction was done. In few cases medullary cavity was absent and had to use reamers. The nail was subsequently advanced across the fracture site with gentle blows and rotatory movements under fluoroscopic control. Care is taken not to penetrate the cortex laterally. The nail is then bend 180 degrees inferiorly, cut and buried under skin. Bending the nail reduced the chances of skin irritation by the sharp cut end of nail. Skin was then closed with sutures.

Post-operatively patient was put on an arm pouch. Check x-ray was taken and pendulum exercises were begun immediately. Active mobilization was started depending on pain tolerance. Arm pouch was discarded at one month and overhead activities were allowed. Further x-rays were taken at 6 weeks, 3 months and six months.

The nail was removed once fracture union was confirmed clinically and radiologically. Functional outcomes were assessed with costant shoulder score at 6 weeks, 3, 6 and 12 months post-surgery. Clavicle lengths were measured clinically at 12 months and compared with the opposite side.

\section{Results}

Out of 30 patients 26 were males and 4 were females. Sixty percent injuries resulted from road accidents and $40 \%$ from fall. Mean age was 31.5 ranging from 18 to 60 years. Right side was involved in $20(66.7 \%)$.

One patient had a segmental fracture of midshaft and 10 had a butterfly fragment. Two were type 1 open 
fractures. Open reduction was needed in $15(50 \%)$ patients. The segmental fracture was done closed. Average operating time was 45 minutes.

All fractures united without infection or antegrade migration of implant. The average healing time was 13.6 weeks. The mean Constant score at 6 weeks was 56.98 (44-72), at 3 months was 91.25, at 6 months was 96.38 and at one year it was 98.75. In three cases, the nail end had to be trimmed due to prominent hardware irritation although $14(46 \%)$ patients complained of implant prominence without much irritation.

All implants were removed under local anesthesia as a day care surgery. The average clavicle shortening was $6 \mathrm{~mm}$ ( $3 \mathrm{~mm}$ to $14 \mathrm{~mm})$, and more shortening was observed in fractures with comminution.

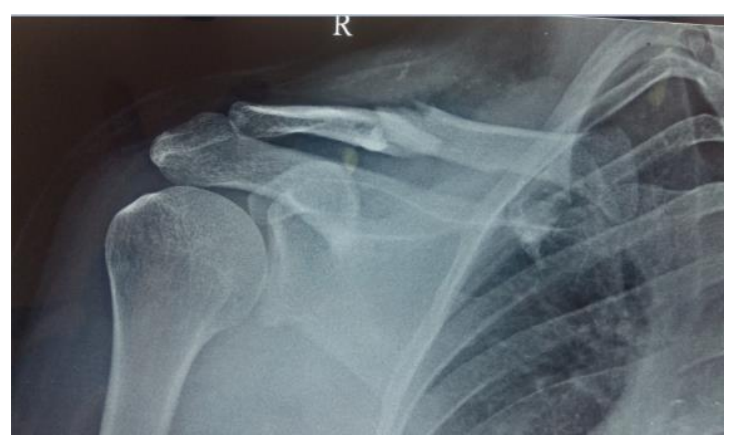

Fig. 1: Pre operative $x-r a y$

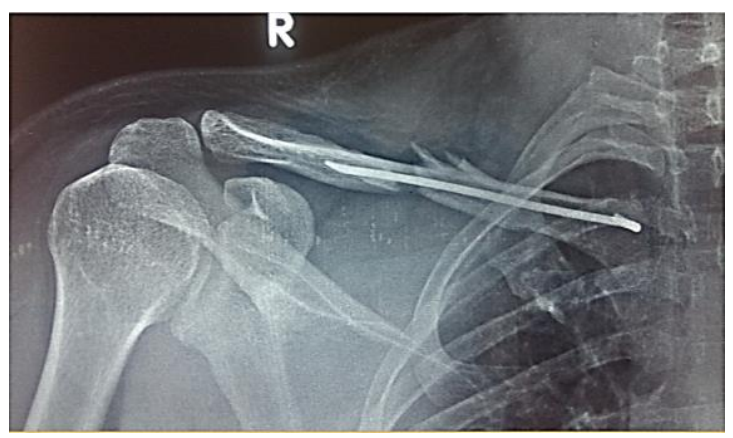

Fig. 2: Post operative x-ray

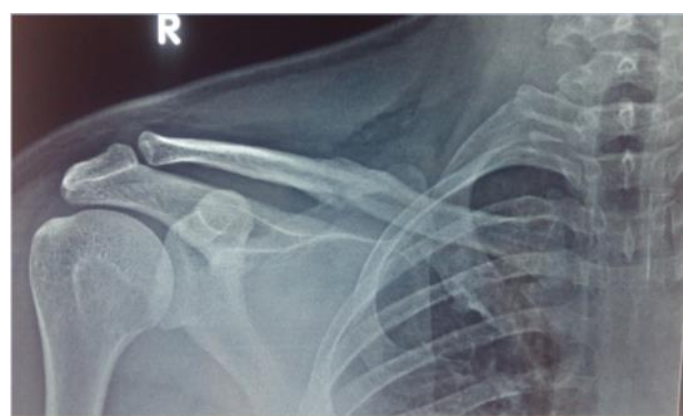

Fig. 3: After implant removal

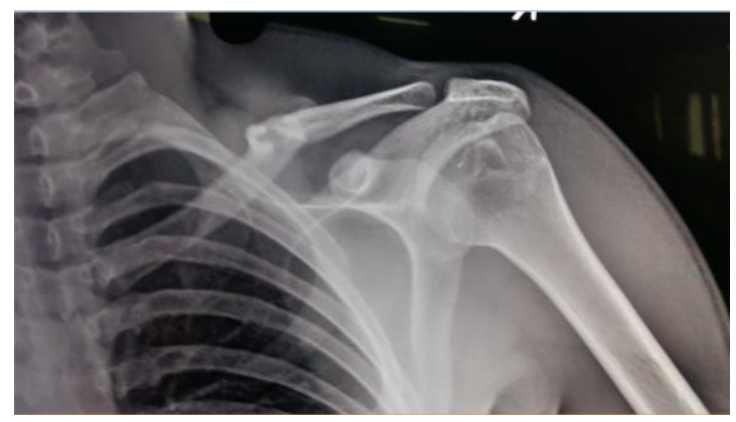

Fig. 4: Pre-op x-ray

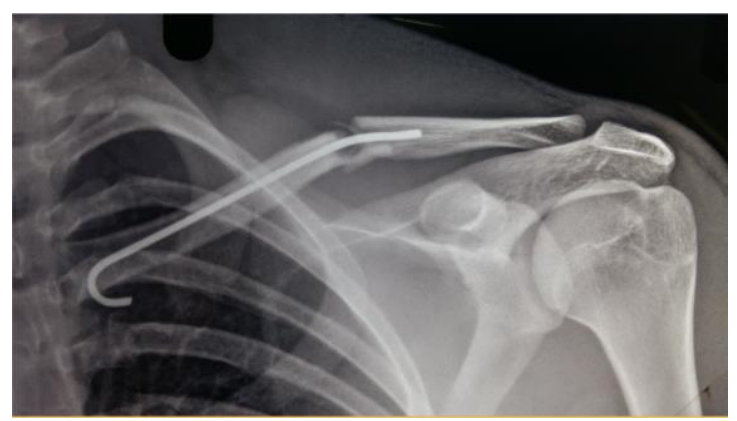

Fig. 5: Post op x-ray

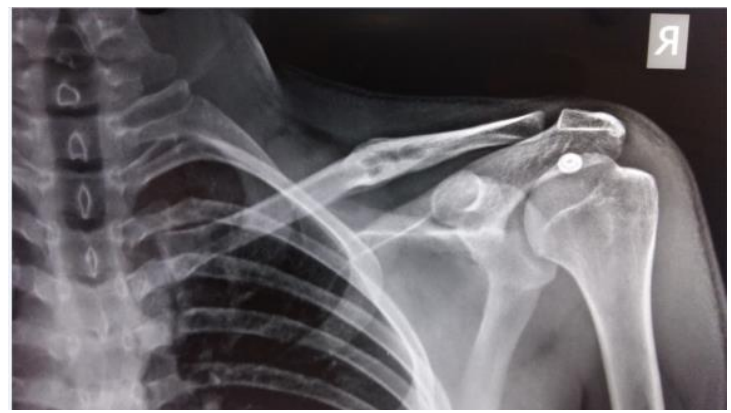

Fig. 6: After healing

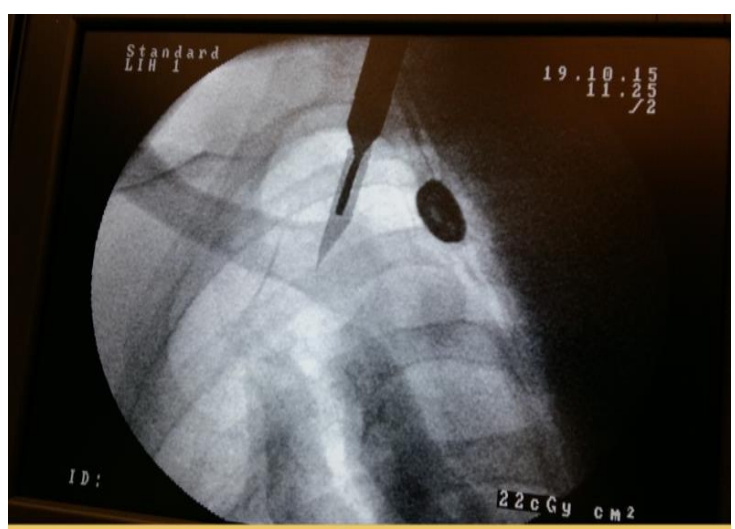

Fig. 7: Intra operative flouroscopy showing entry site for the nail.

\section{Discussion}

The treatment of displaced mid-clavicular fractures is shifting from old concept of conservative treatment towards surgical fixation based on recent evidences. ${ }^{4-6}$ The problems of prolonged immobilization and delay in 
going back to work are avoided by surgical fixation. Plate osteosynthesis is an expensive major surgery which leaves a large scar and has high incidence of supraclavicular nerve damage. ${ }^{11}$ Plate removal is a major procedure and associated with increased risk of refracture after removal. ${ }^{11}$ Titanium elastic nailing is simpler, cheaper and cosmetically well accepted. ${ }^{10}$ But it has a disadvantage of increased radiation exposure and not suitable for severely comminuted fractures. Nail removal can be done under local anaesthesia.

Wick et $\mathrm{al}^{12}$ and Eskola et $\mathrm{al}^{13}$ observed high rates of non-union, shoulder pain and poor functional outcome when the fracture heals with more than $2 \mathrm{~cm}$ shortening. Even though plate fixation is the gold standard, minimally invasive elastic nailing is an established alternative.

In our study elastic nailing provided early functional recovery. In this fast world patients expect rapid and pain free functional recovery following a fracture. In contrast to conservative treatment, elastic nailing can fulfill theses expectations without much complications. The functional outcome of nailing was comparable to plating. ${ }^{10,14}$ The most common complication of nailing is hardware prominence at the sternal end. Most of the patients complained about the nail prominence but tolerated it well till nail removal. The three cases in which we had to trim the nail had comminution. Collapse at the comminuted fracture site lead to medial backing of the nail which is well documented in literature also. ${ }^{10,15}$ The clavicle lengths were maintained in most cases and the shortening observed is also within acceptable range. ${ }^{10,15}$

\section{Conclusion}

The treatment of mid-clavicular fractures remains a subject of controversy. The consensus is moving more towards surgical fixation and elastic nailing is a safe and minimally invasive option. It is cosmetically superior and less expensive compared to locking plates. But in severely comminuted fractures plating is superior.

Elastic nailing results in quicker return to daily activities, small scar, excellent functional outcome and high patient satisfaction rates. It is a good technique for mid-clavicular fracture fixation and can be an alternative to conservative treatment as it allows earlier rehabilitation. In summary, we believe that elastic nailing of mid-clavicular fractures is a cheaper and safe method with excellent functional outcome.

\section{References}

1. Nordqvist A, Petersson C. The incidence of fractures of the clavicle. Clin Orthop. 1994;300:127-132.

2. Postacchini F, Gumina S, De Santis P, Albo F. Epidemiology of clavicle fractures. J Shoulder Elbow Surg. 2002;11:452-6.

3. Nordqvist A, Petersson C. The incidence of fractures of the clavicle. Clin Orthop Relat Res. 1994;300:127-32.
4. Canadian Orthopaedic Trauma Society. Nonoperative treatment compared with plate fixation of displaced midshaft clavicular fractures. A multicenter, randomized clinical trial. J Bone Joint Surg Am. 2007;89:1-10.

5. Hill JM, McGuire MH, Crosby LA. Closed treatment of displaced middle- third fractures of the clavicle gives poor results. J Bone Joint Surg Br. 1997;79:537-9.

6. Wild LM, Potter J. Deficits following nonoperative treatment of displaced midshaft clavicular fractures. $J$ Bone Joint Surg. 2006;88-A:35- 40.

7. Denard PJ, Koval KJ, Cantu RV, Weinstein JN. Management of midshaft clavicle fractures in adults. $\mathrm{Am}$ J Orthop (Belle Mead NJ). 2005;34:527-36.

8. Kettler M, Schieker M, Braunstein V, Konig M, Mutscher W. Flexible intramedullary nailing for stabilization of displaced midshaft clavicle fractures: technique and results in 87 patients. Acta Orthop. 2007;78:424-9.

9. Grassi FA, Tajana MS, D'Angelo F. Management of midclavicular fractures: comparison between nonoperative treatment and open intrameduallary fixation in 80 patients. $J$ trauma. 2001;50:1096-1100.

10. Saha P, Dutta P, Ayan S, Garg AK, Bandyopadhyay U, Kundu S. Plate Versus titanium elastic nail in treatment of displaced mid clavicle fractures A comparative study. Indian J Orthop. 2014;48:587-93.

11. Canadian Orthopaedic Trauma Society (2007) Nonoperative treatment compared with plate fixation of displaced midshaft clavicular fractures. A multicenter, randomized clinical trial. J Bone Joint Surg Am. 2007;89:1-10.

12. Wick M, Muller EJ, Kollig E, Muhr G. Midshaft fractures of clavicle with a shortening of more than $2 \mathrm{~cm}$ predispose to nonunion. Arch Orthop Trauma Surg. 2001;121:207-11.

13. Eskola A, Vainionpaa S, Myllynen P, Patiala H, Rokkanen P. The outcome clavicular fractures in 89 patients. Arch Orthop Trauma Surg. 1986;105:337-338.

14. Chen YF, Wei HF, Zhang C, Zeng BF, Zhang CQ, Xue $\mathrm{JF}$ et al. Retrospective comparison of titanium elastic nail and reconstruction plate repair of displaced midshaft clavicular fractures. J Shoulder Elbow Surg. 2012;21:495-501.

15. Lazarides $\mathrm{S}$, Zafiropoulos G. Conservative treatment of fractures at the middle third of clavicle: the relevance of shortening and clinical outcome. J Shoulder Elbow Surg. 2006;15:191-4.

How to cite this article: Gopalakrishnan A, Sreesobh KV, Jose J. Functional outcome of titanium elastic nailing in midclavicular fractures. Indian J Orthop Surg. 2018;4(3):270-272. 